Research Paper

\title{
Antineoplasic Effect of Aqueous Extract of Plectranthus Amboinicus in Ehrlich Ascites Carcinoma
}

\author{
Eduardo M. Brandao ${ }^{\circledR}$, Paulo H. D. M. Brandão², Ivone A. Souza 3 , Gerson S. Paiva ${ }^{4}$, Marcos de C. Car- \\ valho ${ }^{4}$, Claudio M. Lacerda ${ }^{5}$ \\ 1. Department of Oncology, School of Medicine,University of Pernambuco (UPE); \\ 2. Department of Surgery, Holy House of Mercy Hospital, São Paulo; \\ 3. Department of Antibiotics, Federal University of Pernambuco (UFPE); \\ 4. Brazilian Center for Physics Research (CBPF); \\ 5. Department of Surgery and Liver Transplantation, School of Medicine, University of Pernambuco (UPE).
}

$\triangle$ Corresponding author: Eduardo Miranda Brandão. Rua Manuel de Carvalho 114. Aflitos. Recife. PE. Brazil. CEP 52050-370. Phone (55)-081-34270019. E-mail emiranda.onco@gmail.com.

(c) Ivyspring International Publisher. This is an open-access article distributed under the terms of the Creative Commons License (http://creativecommons.org/ licenses/by-nc-nd/3.0/). Reproduction is permitted for personal, noncommercial use, provided that the article is in whole, unmodified, and properly cited.

Received: 2013.05.20; Accepted: 2013.07.21; Published: 2013.08.20

\begin{abstract}
There are 46,000 new cases of peritoneal carcinomatosis per year in the USA and 17,700 in Brazil. New media, including plant derivatives, are being tested in its treatment. Plectranthus amboinicus is a medicinal plant widely used in Brazil, especially in the northeast region, for the treatment of various diseases, including cancer. This present study evaluates the intraperitoneal use of aqueous extracts of Plectranthus amboinicus (AEPa) at a dose of $200 \mathrm{mg} / \mathrm{kg}$ for the treatment of the ascitic form of Ehrlich carcinoma. It is concluded also the AEPa produced antineoplastic effect in ascitic form of Ehrlich carcinoma.
\end{abstract}

Key words: Peritoneal carcinomatosis; Plectranthus amboinicus (Pa); Ehrlich ascites carcinoma (EAC); Aqueous extract of Plectranthus amboinicus (AEPa).

\section{Introduction}

Peritoneal carcinomatosis is a prominent theme in oncology today in view of its incidence, with approximately 46,000 new cases annually in the U.S. and 17,700 in Brazil. Its high mordibity and mortality has made it necessary to investigate new forms of treatment, including the systemic and intrarperitoneal use of plant derivatives [1-3].

The Plectranthus genus comprises approximately 300 species occurring in Asia, Africa and Australia, while the amboinicus species is native to Asia, but is also found in the Americas [4]. It is popularly known in Brazil as "thick mint leaf ". Pharmacological studies have demonstrated antioxidant and cytotoxic properties in this plant [5-7].

Its leaves contain essential oils, flavonoids, cinaminics and terpene derivatives, all of which have antineoplastic properties.
The empirical use of Plectranthus amboinicus in Brazil occurs in several areas, especially in the northeast region in the form of infusion with crude extract for the treatment of various disorders such as inflammations and tumors.

In order to provide scientific support to these observations an in vivo study was conducted using hydroalcoholic extract from the leaves of the Plectranthus amboinicus (HEPa) used intraperitoneally in the treatment of the solid form of Ehrlich carcinoma cells implanted into the subcutaneous tissue of mice [8].

The doses of $100 \mathrm{mg} / \mathrm{kg}$ and $150 \mathrm{mg} / \mathrm{kg}$ of HEPa resulted in decreases of $74 \%$ and $61 \%$, respectively, in the size of the tumors.

This present study evaluates the intraperitoneal use of aqueous extracts of Plectranthus amboinicus 
(AEPa) at a dose of $200 \mathrm{mg} / \mathrm{kg}$, intraperitoneally, for the treatment of the ascitic form of Ehrlich carcinoma. A comparative evaluation was made of the two groups of mice and the clinical data and biometric, cytometric and cytomorphological parameters recorded.

\section{Materials and methods}

\section{I. Plant material and extract}

Plectranthus amboinicus (Pa) leaves from the herbarium of the Laboratory of Pharmaceutical Technology, Federal University of Paraiba were collected and identified, a sample of which was deposited at the herbarium of the Pernambuco Agricultural Research Institute-IPA. Maceration of the leaves was conducted in natura using a dilution with saline to yield the crude aqueous extract (AEPa). A solution of .AEPa was obtained and stored in refrigeration of 4 degrees $\mathrm{C}$.

\subsection{Animals}

The animals used were female mice of the Swiss albino species (Mus musculus) with a mean weight of $30 \mathrm{~g}$ and aged approximately 60 days. The animals were kept in a vivarium at the Department of Antibiotics UFPE, packed in plastic box-type cages with grids measuring $20 \mathrm{~cm}$ (width) x $30 \mathrm{~cm}$ (length) $\times 12$ $\mathrm{cm}$ (height), on a shelf in a horizontal position and floor lined with pine shavings. Conventional sanitary cleaning of the cages and a change of shavings were carried out every three days.

The cages were kept in a cool environment at a mean temperature of $22+/-2^{\circ} \mathrm{C}$ in relative humidity and a light-dark cycle. The animals were fed industrialized food for rodents (Labina ${ }^{\circledR}$ ) and water ad libitum. Six animals were assigned to the experimental group G1 (G1A to G1F) and the other six to the control group G2 (G2A to G2F).

On the first day (D1) of the experiment the animals in both the treated (G1) and control groups (G2) were injected 2,500,000 tumor cells with $0.3 \mathrm{ml}$ of as-

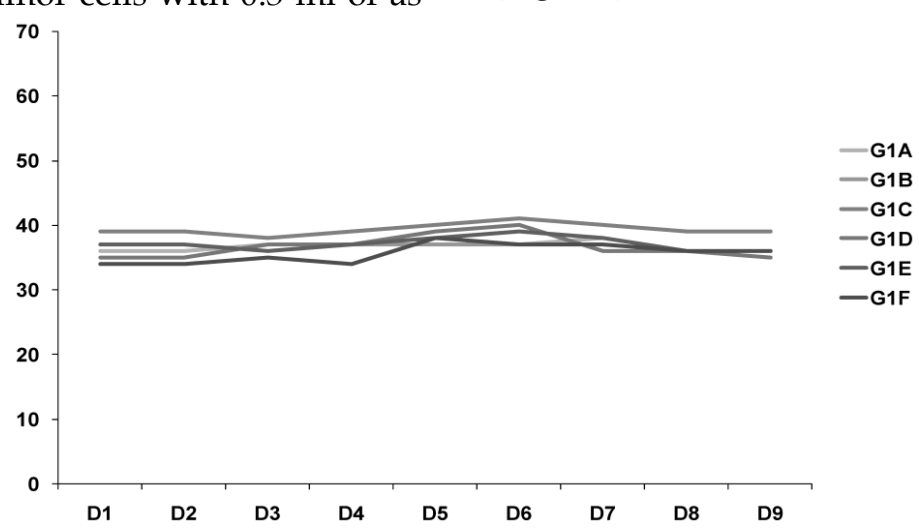

citic fluid of Ehrlich carcinoma. On D3 a clinical evaluation was performed, consisting of measurement of the weight, assessment of mobility and piloerection. Daily abdominal measurements were also made. From D3 to D9 a $200 \mathrm{mg} / \mathrm{kg}$ dose of AEPa and an $0.5 \mathrm{ml}$ dose of saline were injected intraperitoneally in G1 and G2, respectively.

On the ninth day of the experiment (D9) the animals were euthanized and an evaluation made of the ascites and presence of implants in the abdominal wall. Cytometric analysis was performed with a total leukocyte and Ehrlich carcinoma cell count and cytology using the Pap modified technique to compare the two groups.

The experiment was carried out in accordance with the ethical principles of the Brazilian College of Animal Experimentation and the National Institute of Health Guide for Care and Use of Laboratory Animals. The study was approved by the UFPE Committee on Animal Experimentation (protocol \# 23076.043890/2011-27).

\section{Statistical analysis}

Owing to the small number of observations, Fisher's Exact test was used to compare the qualitative variables in the two groups. The nonparametric Mann-Whitney test was used to compare the quantitative variables. To verify changes in weight in each group the Wilcoxon test was carried out. We chose to use only nonparametric methods because of the small size of the sample. The significance level was $5 \%$. Statistical calculations were performed with SPSS for Windows version 18.0.

\section{Results}

In relation to the weight of the animals, it was observed that over the 9 days there was stabilization of weight in G1 and an increase in G2, which was statistically significant $(p=0.027)$. This may indicate a greater increase in ascites in the untreated group (G2) (Fig. 1-2).

Fig. I. Weight of the animals (Treated goup) GI - G2 animals/ DI- D9. 


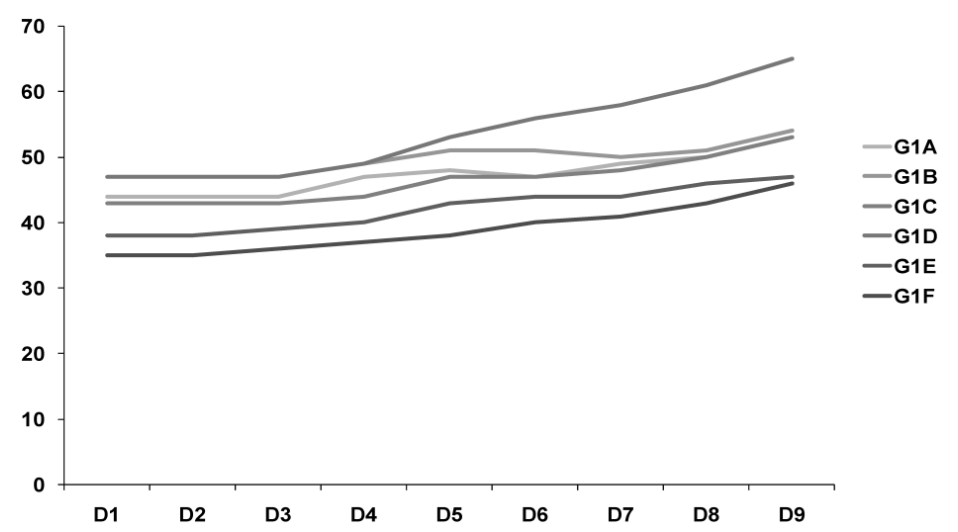

Fig. 2. Weight of the animals (Control goup) GI - G2 animals/ DI- D9.

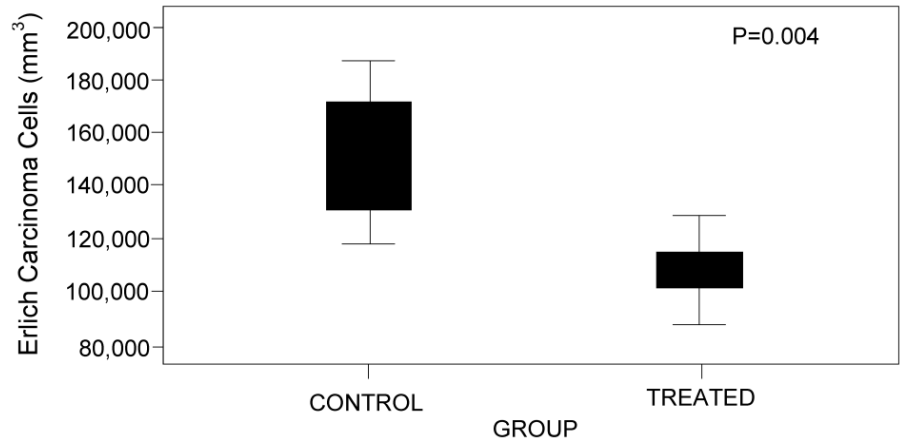

Fig. 3. Comparative box plot of carcinoma cells between the groups.

There were no significant changes in mobility in either group. In G1 piloerection was observed in all animals from D4, which may be interpreted as being due to the toxicity of the components of the AEPa.

In Table I, when the groups are compared with respect to the volume of ascites, there is a statistically significant difference: $2.58 \mathrm{ml}$ in G1 and $12.97 \mathrm{ml}$ in G2 $(\mathrm{p}=0.002)$.

Implants in the abdominal wall were found in $66.7 \%$ of the G2 animals, but were not present in any of the G1 ones. This characterizes the tendency of AEPa to influence such an occurrence.

As regards the number of Ehrlich carcinoma cells counted in both groups, a statistically significant lower percentage was observed in GI, which is indicative of an objective aspect of tumor response to AEPa $(\mathrm{p}=0.004)$ (Fig. 3).

No differences were noted between the groups in relation to the following: increased nuclear volume, hyperchromasia, abnormal nucleus-cytoplasm ratio, irregular nuclear contour, unevenly distributed chromatin, abnormal or multiple nucleoli and atypical mitoses.
Table I: Descriptive statistics of ascites volume (ml) according to group

\begin{tabular}{llllll}
\hline Group & \multicolumn{6}{l}{ Volume of Ascites } \\
\cline { 2 - 6 } & Mean & S D & Median & Minimum & Máximum \\
\hline Treated (G1) & 2,58 & 0,35 & 2,45 & 2,30 & 3,20 \\
Control (G2) & 12,97 & 5,28 & 11,65 & 7,70 & 20,20 \\
Total & 7,77 & 6,49 & 5,45 & 2,30 & 20,20 \\
\hline
\end{tabular}

$p=0.002$

Table II - Incidence of implants in the abdominal wall

\begin{tabular}{llllll}
\hline & & \multicolumn{3}{l}{ Group } & \\
\cline { 3 - 6 } & & & Control & Treated & Total \\
\hline $\begin{array}{l}\text { Tumor implant in } \\
\text { abdominal wall }\end{array}$ & Absent & $\mathrm{N}$ & 2 & 6 & 8 \\
& & $\%$ & $33,3 \%$ & $100,0 \%$ & $66,7 \%$ \\
& \multirow{2}{*}{ Present } & $\mathrm{N}$ & 4 & 0 & 4 \\
& & $\%$ & $66,7 \%$ & $0,0 \%$ & $33,3 \%$ \\
& \multirow{2}{*}{ Total } & $\mathrm{N}$ & 6 & 6 & 12 \\
& & $\%$ & $100,0 \%$ & $100,0 \%$ & $100,0 \%$ \\
\hline
\end{tabular}

$\mathrm{p}=0.051$ (Fisher's Exact test) 


\section{Discussion}

An experiment was designed in which a derivative of the plant Plectranthus amboinicus was used intraperitoneally for the treatment of peritoneal carcinomatosis caused by Ehrlich ascites carcinoma, based on previous studies using this plant to treat this kind of tumor in its solid form [8-9].

With regard to the dosage of AEPa used $(200 \mathrm{mg}$ / $\mathrm{kg}$ ), it should be noted that this dose was similar to that producing the highest responses observed in a previous study with the solid form of Ehrlich carcinoma, consisting of the use of a hydroalcoholic derivative of Pa injected intraperitoneally at doses of 100 and $150 \mathrm{mg} / \mathrm{kg}$, with decreases in tumor volume of $74 \%$ and $61 \%$, respectively, no increase in response occurring with doses greater than $200 \mathrm{mg} / \mathrm{kg}$ [9]..

In this study the mean total count of Ehrlich carcinoma cells in the ascites samples was 106,668.83 cells / $\mathrm{mm} 3$ in the treated group (G1) versus 145,318.33 cells $/ \mathrm{mm} 3$ in the control group (G2) $(\mathrm{p}=0.004)$. Thus, an objective result of response to AEPa was obtained.

With regard to the cytological features of the seven items morphologically analyzed in a standardized fashion by a highly experienced cytologist who had no prior information regarding the group of slides examined, no differences were observed between the treated and control groups.

The interpretation of this finding is paradoxical, especially when compared with objective evidence of the response in the group treated with the EAPa, such as the lower abdominal measurement, lower percentage of ascites and implants in the abdominal wall and, particularly, the Ehrlich carcinoma cell count.

It may be assumed that the cytomorphological effect of AEPa would be manifested only over periods longer than that of the present study and also that more refined methods of analysis, such as immunocytochemistry and silver staining for the evaluation of nucleolar organizer regions (AgNORs), may improve the results. The latter method makes it possible to calculate the percentage and ratio of dark and light cells, suggesting their proliferative potential, and may be of value in further studies.

In addition, the present study corroborates the antineoplastic effect of $\mathrm{Pa}$ and paves the way to further analysis with the fractionation of the components of this plant that have highlighted its antitumor effect.

\section{Conclusion}

It was found that the AEPa produced a better control of ascites and a lower tumor cell count in the ascitic fluid. There were no cytomorphological differences between the two groups. It is concluded also the AEPa produced antineoplastic effect in ascitic form of Ehrlich carcinoma.

\section{Acknowledgements}

The authors wish to thank Prof. Marcio Melo from the Marcelo Magalhães Laboratory and Prof. Daisy Lima from the CICC Laboratory for their valuable assistance.

\section{Competing Interests}

The authors have declared that no competing interest exists.

\section{References}

1. Vieira JR, de Souza IA, do Nascimento SC, Leite SP. Indigofera suffruticosa: An alternative anticancer therapy. Evid Based Complement Alternat Med. 2007 Sep;4(3):355-9.

2. Pagno T, Blind LZ, Biavatti MW, Kreuger MR. Cytotoxic activity of the dichloromethane fraction from Vernonia scorpioides (Lam.) Pers. (Asteraceae) against Ehrlich's tumor cells in mice. Braz J Med Biol Res 2006; 39 (11): 1483-91.

3. Hamilton CA, Maxwell GL, Chernofsky MR, Bernstein SA, Farley JH, Rose GS. Intraperitoneal bevacizumab for the palliation of malignant ascites in refractory ovarian cancer. Gynecol Oncol. 2008, 111:530-2.

4. Acosta LMR, Fuentes V, Rodriguez C. Instructional coach del Plectranthus amboinicus (Lour.) Spreng. Rev. Plants Medicinales.1998;3 :51-53.

5. Salman JGD, Jimenez TEG, Castilho RM. Efecto antoxidante de los extractos fluidos y flavonoides del Plectranthus amboinicus (Louur.) Spreng. Oregano French. Revista Cubana de Medicinal Plants 1996.2:27-30.

6. Hirose $\mathrm{M}$, et al. Effects of ellagic acid, and quercitin vanilin in a rat medium-term multi-organ carcinogenesis model. Cancer Letters, 1995;94:113-121.

7. Carrazoni EP. Medicinal plants of popular use. Recife: Fasa; 2000.

8. Gurgel APAD, et al. study of the in vivo anti-inflamatory and Antitumor Activities of leaves from Plectranthus amboinicus (Lour) Spreng (Lamiaceae). Journal of Ethnopharmacology 2009; 125: 361-363.

9. Gurgel PD. The importance of Plectranthus amboinicus (Lour.) Spreng alternative therapy-experimental methods; Master Thesis in Pharmaceutical Sciences. UFPE. 2007. 